\title{
Flexible pavement design for hot climates - a case study
}

Kranthi Kuna BE, MTech, PhD

Pavement Engineer, Mott MacDonald Ltd, Southampton, UK (corresponding author: k.kranthi13@gmail.com)
Kieran Kelly BEng, MSc, CEng, MICE

Pavement Engineer, Mott MacDonald Ltd, Southampton, UK

This paper discusses the application of best practice and lessons learnt in pavement design for hot climates through the presentation of a case study from a large highway project in the State of Qatar. The environmental conditions experienced in hot climates pose several challenges for engineers when designing a pavement capable of surviving its anticipated service life. The predominant challenge is developing realistic predictions of asphalt modulus as an input into analytical pavement design. There is also a challenge in ensuring that inputs into empirical designs reflect the local environment and the properties of materials used. This paper discusses how international design practice, knowledge and research of pavement materials were translated into design and, subsequently, construction. The process of developing and selecting design inputs for empirical and analytical design approaches is discussed. The paper also highlights the best practices associated with the design of pavements with a cement-stabilised base.

\section{Notation}

$a(T) \quad$ shift factor for test temperature $T$

$C_{1}, C_{2} \quad$ regression constants in the Williams-Landel-Ferry equation

$E^{*} \quad$ dynamic modulus

f vehicle loading frequency

$f_{\mathrm{CY}} \quad$ test frequency in dynamic modulus test

$f_{\mathrm{PR}} \quad$ test frequency in flexural modulus test

$f_{\mathrm{r}} \quad$ reduced frequency in dynamic modulus master curve

$i \quad$ pavement temperature condition class

$k \quad$ number of pavement temperature condition classes

$N_{i} \quad$ design traffic for a constant temperature condition class $i$

$N\left(T_{\text {eq }}\right) \quad$ design traffic for a constant equivalent pavement temperature

$n_{i} \quad$ proportion of traffic during pavement temperature condition class $i$

$T \quad$ test temperature in dynamic modulus test

$T_{\text {eq }} \quad$ equivalent pavement temperature

$T_{\mathrm{r}} \quad$ reference temperature at which master curve is derived

$t \quad$ vehicle loading time

$V \quad$ vehicle speed

$Z \quad$ depth from surface of asphalt

$\alpha, \beta, \gamma, \delta \quad$ sigmoidal model parameters

$\Delta \quad$ total deformation in indirect tension test

$\Delta_{\mathrm{r}} \quad$ resilient deformation in indirect tension test

\section{Introduction}

Pavement design in the hottest parts of the world poses a number of challenges for designers. High temperatures influence the choice of materials, the analysis of those materials in the design process, construction and overall performance during the service life of the pavement. The focus of this paper is on the selection of design parameters for hot climates similar to the Middle East, but the methodology is relevant to any climatic conditions.

Asphalt is one of the most widely used pavement materials and its performance is dependent on both temperature and time (i.e. traffic speed). High temperatures mean a lower elastic modulus in service, exposure to high levels of ultraviolet light increases the rate of hardening, and asphalt mixtures must also be designed using a binder type and content that will resist defects such as permanent deformation and bleeding. Additionally, the effects of temperature on lower layers such as cement-bound bases must also be considered because, although their performance is not strictly temperature dependent, the effects of high temperatures can influence constructability, particularly in terms of ensuring proper curing takes place and shrinkage cracking is minimised.

This paper focuses on the application of best practice in the design of pavements for a project in the State of Qatar. Figure 1 shows typical photographs of the project area. Particular attention was paid to traditional analytical pavement design inputs.

An analytical design approach is divided into two steps: pavement response prediction and pavement performance prediction. Pavement response (e.g. tensile strain at the bottom of the asphalt base) is estimated from a structural model (e.g. multilayered elastic theory) using initial, undamaged properties of the layer materials. Material performance models are developed using laboratory tests results and relate the initial response of specimens to the life of those specimens. The pavement responses estimated from the structural model are then input into a calibrated performance model to determine the life of the pavement. This approach is adopted in most pavement design methods. 


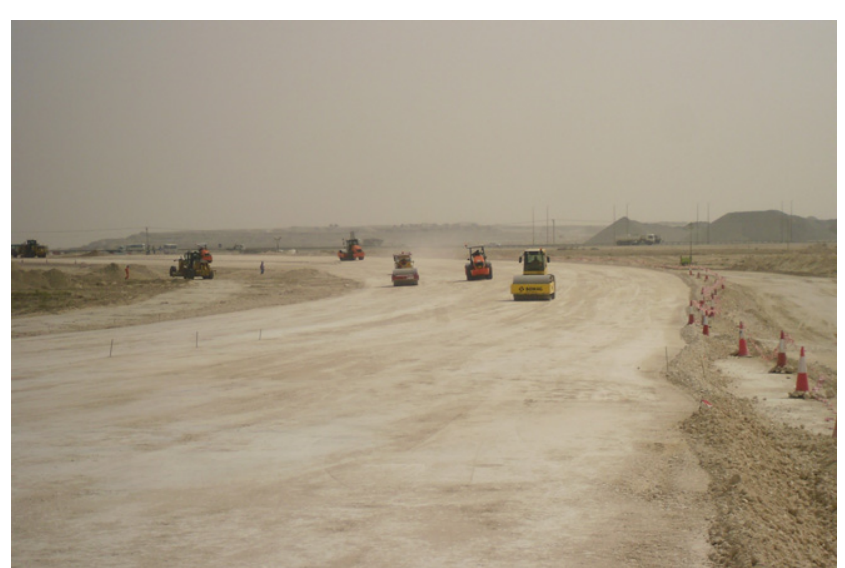

(a)

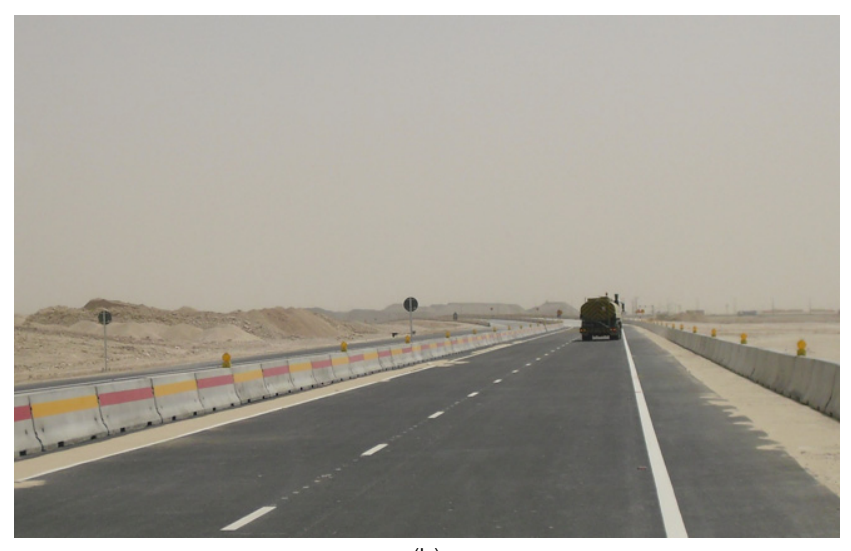

(b)

Figure 1. Typical local existing ground/subgrade (a) and highway (b)

Although more advanced and well-developed pavement response predictions based on finite-element models (FEMs) and the discrete-element method are available, they require specialist resources and more time to characterise the materials, in addition to added complexity. Moreover, most of the existing pavement design methodologies (e.g. Austroads, 2012; Highways England, 2006; LCPC and Setra, 1997) are based on multi-layer linear elastic models. Therefore, the scope of this paper is limited to the selection of design inputs for linear elastic analysis and design.

\section{Challenges}

Pavement structures must be capable of functioning adequately over their design life under in-service climatic conditions. In hot countries like Qatar, where pavement surface temperatures can reach $70^{\circ} \mathrm{C}$, the most important performance requirements for asphalt mixtures are resistance to permanent deformation (rutting) and resistance to surface cracking induced by ageing. In addition to these issues, high temperatures significantly reduce the stiffness of asphalt layers. In view of these challenges, asphalt bases are usually designed to a low bitumen content in order to reduce temperature sensitivity. For example, the target bitumen contents for typical surface and base courses in the UK are $4 \%$ and $4.7 \%$ respectively (BSI, 2010). Corresponding values for design mixes specified in Qatar are in the region of $3.6 \%$ and $4.2 \%$, respectively.

The selection of bitumen has a great influence on the performance requirements of surface and/or intermediate courses. Elastomerically modified bitumen, which usually provides better resistance to rutting and cracking over a wide range of temperatures, was specified in the design requirements for the case study under consideration. The polymer-modified bitumen used in the asphalt was graded as PG 76-10.

Preliminary structural and economic analysis identified that, at lower traffic levels (approximately $15 \mathrm{msa}$ (million standard axles), a fully flexible pavement required an asphalt surface of approximately $200 \mathrm{~mm}$ thickness, varying slightly with traffic loading. At higher traffic loads, typically over $50 \mathrm{msa}$, a flexible composite alternative became more advantageous. This pavement consisted of a variable thickness of cement-bound material (CBM) with a $7 \mathrm{~d}$ unconfined compressive strength of $4 \cdot 5 \mathrm{MPa}$, surfaced with a minimum of $190 \mathrm{~mm}$ of asphalt. This pavement was beneficial as it minimised asphalt thickness and reduced overall construction costs.

\section{Design inputs}

Figure 2 shows a flow chart for mechanistic analysis and typical design inputs required for flexible pavement design using a layer elastic response model. As shown in the figure, the traffic composition of the pavement and the elastic properties of the material are the primary design inputs in the design of the asphalt pavements. For pavements in hot climates, particular attention should be paid to the asphalt stiffness modulus because of its temperature-sensitive behaviour. For example, asphalt stiffness changes by a factor of about three for every $10^{\circ} \mathrm{C}$ temperature change and stiffness is a key input into the calculation of pavement response.

Viscoelasticity and temperature dependency are accounted for in the pavement analysis by determining the viscoelastic characteristics from dynamic modulus master curves. A dynamic modulus master curve indicates the material's stiffness modulus across a range of test frequencies. These frequencies can then be correlated to speed and temperature, enabling a designer to estimate the material stiffness for a range of parameters. For example, the US mechanistic empirical pavement design guide (MEPDG) (ARA, 2001) uses the asphalt master curve to express the range of intrinsic viscoelastic behaviour of asphalt.

Most alternative design methods (Asphalt Institute, 1981; Austroads, 2012; Highways England, 2006; LCPC and Setra, 1997) use a single value of stiffness modulus at a single temperature and single loading condition. Therefore, the stiffness modulus should be determined at a representative temperature 


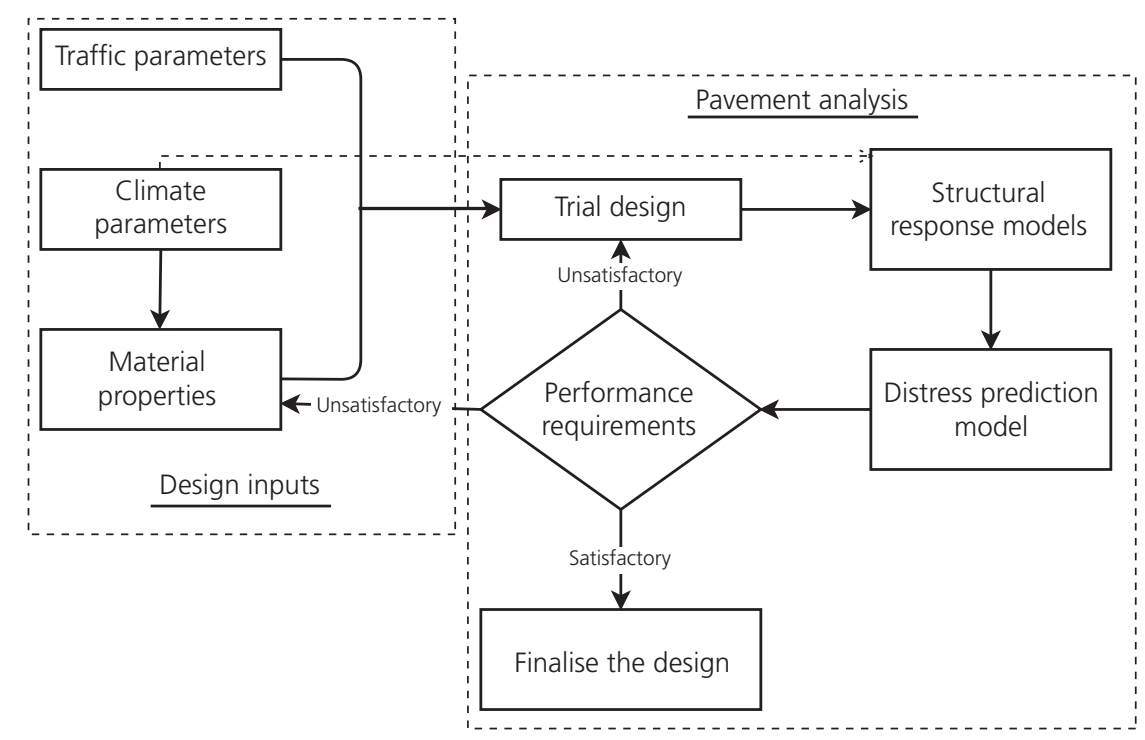

Figure 2. Flow chart for design of a flexible pavement

(i.e. the design temperature) and frequency/loading before used in the design.

\subsection{Design temperature}

The most significant environmental factor affecting the performance of asphalt pavements is temperature. The temperature to which a pavement is exposed influences pavement distress mechanisms and performance. The incorporation of this temperature factor is critical in analytical design, as previously explained, and most design methods use a single temperature as a design input. This temperature is called the equivalent (effective) pavement temperature $\left(T_{\text {eq }}\right)$. At least two approaches to the calculation of $T_{\mathrm{eq}}$ can be found in the literature, which are based on Miner's damage hypothesis. The definition incorporated in the Shell pavement design method (Shell, 1978) is that the response (stress or strain) induced by a standard wheel load, at the effective temperature, is a weighted mean of the response developed by the wheel load across the spectrum of temperatures the pavement will experience during its design life (Claessen et al., 1977). Thus, the equivalent temperature can be calculated using

1. $N\left(T_{\text {eq }}\right)=\frac{k}{\sum_{i=1}^{k}\left(1 / N_{i}\right)}$

where $N\left(T_{\text {eq }}\right)$ is the design life for a constant effective temperature $\left(T_{\text {eq }}\right), N_{i}$ is the design life for a constant temperature condition class ' $i$ ' and $k$ is the number of temperature condition classes.

An alternative definition of $T_{\text {eq }}$ is the constant pavement temperature. Using this factor results in the same life, obtained by summing the damage over the pavement temperatures that will occur during the design life. This approach takes account of the proportion of traffic flow during each pavement temperature class. Therefore, the equivalent temperature is a traffic- and damage-weighted mean temperature, which can be determined by Equation 2. The Highways England design temperature of $20^{\circ} \mathrm{C}$ was derived based on this approach (EC, 1999; Nunn, 2004).

2. $N\left(T_{\text {eq }}\right)=\frac{\sum_{i=1}^{k} n_{i}}{\sum_{i=1}^{k}\left(n_{i} / N_{i}\right)}$

In Equation 2, $n_{\mathrm{i}}$ is the proportion of traffic for a pavement temperature condition ' $i$ ', $k$ is the number of pavement temperature classes and the pavement temperature is function of air temperature and surface temperature.

Adopting these methods to calculate the design temperature requires knowledge of the expected pavement temperature distribution throughout the design life. This information can be collected from pavement measurements or estimated from empirical models such as the BELLS model. Otherwise, it can be calculated from meteorological data such as hourly air temperature, wind speed and precipitation in conjunction with thermal characteristics of the materials used in the pavement. Such an approach is embedded in the MEPDG enhanced integrated climate model.

To determine design temperatures at a project level, chart W of the Shell pavement design manual (Shell, 1978) provides an empirical relationship to derive monthly weighting factors (WFs) using monthly average air temperatures. The significance of the WF is that it accommodates the relative 
impact temperature has on pavement damage and thus the design life.

The monthly WFs are averaged to provide a single WF for the year, which is converted to a single weighted mean annual air temperature (WMAAT). The WMAAT provides the input into an empirical relationship to determine the weighted mean annual pavement temperature (WMAPT). These relationships were developed by Claessen et al. (1977) based on pavement temperature data collected on trial sections representing various climatic conditions. Based on the empirical relationships proposed in the Shell WMAPT approach (Shell, 1978), a design temperature of $42^{\circ} \mathrm{C}$ was calculated using local climatic data for Qatar.

Similar to the Shell model used to predict the equivalent temperature (Shell, 1978), another model was developed by Witczak (1972). The primary difference between these two models is that the Shell model predicts WMAPT while Witczak's temperature model predicts the mean monthly pavement temperature (MMPT), which is a function of mean monthly air temperature (MMAT), as shown in Equation 3. Therefore, to derive the equivalent design temperature, which accounts for temperature gradients throughout the year (or over the design life), a weighted average needs to be calculated assuming uniform traffic flow during the design life.

$$
\text { 3. } \mathrm{MMPT}=\operatorname{MMAT}\left(1+\frac{1}{Z+4}\right)-\frac{34}{Z+4}+6
$$

Here, MMPT and MMAT are in degrees Fahrenheit and $Z$ is the depth from the surface of the asphalt layer in inches.

The Shell model, which was used on the project under consideration here, was adopted by Austroads (2012) while the Asphalt Institute's pavement design (Asphalt Institute, 1981) adopted Witczak's model for predicting design (equivalent) temperature. The design temperature for this project was found to be $42^{\circ} \mathrm{C}$.

\subsection{Asphalt stiffness modulus}

As already noted, the viscoelastic properties of asphalt mean that vehicle speed (or rate of loading) also affects the stiffness modulus: the slower the vehicle the lower the stiffness modulus. The speeds applied to the project sections, based on local conditions, were $100 \mathrm{~km} / \mathrm{h}$ for mainline sections, $50 \mathrm{~km} / \mathrm{h}$ for loops/ramps and $80 \mathrm{~km} / \mathrm{h}$ for collectors/distributors.

The stiffness modulus is traditionally measured in three different stress states: compression and/or tension (dynamic modulus), bending (flexural modulus) and indirect tension (resilient modulus/indirect tensile stiffness modulus (ITSM)). The shear modulus (shear stress state) was studied along with the dynamic modulus as a potential test to include in the
MEPDG, as a part of the first strategic highway research programme. However, a study by Witczak et al. (2000) compared shear modulus and dynamic modulus tests and concluded that the shear modulus cannot be used in pavement design applications where asphalt stiffness is needed. Therefore, only the dynamic modulus test was selected for use in the new American Association of State Highway and Transportation Officials (AASHTO) pavement design guide (AASHTO, 1993) as an asphalt design input and this replaced the resilient modulus test.

However, bituminous binders are commonly characterised in shear stress mode using a dynamic shear rheometer. While each of these tests measures the asphalt stiffness modulus, not all have the same definition of stiffness modulus. Therefore, it is important to use the stiffness modulus determined by the appropriate test required by the chosen pavement design methodology.

\subsubsection{Flexural and dynamic moduli}

Although testing in indirect tensile mode (ASTM, 2011; BSI, 1993, 2012; SA, 1995) is a widely used laboratory test to characterise asphalt, the complex modulus (flexural and dynamic) is widely adopted as an analytical design input. For example, Austroads (2012), Highways England (2006) and LCPC and Setra (1997) have adopted the flexural modulus while the MEPDG adopts the dynamic modulus.

It is important to recognise that the required loading conditions and test temperatures are different for each methodology. Therefore, each test does not provide directly comparable or interchangeable results.

For example, Highways England (2006) requires the stiffness modulus at a loading frequency of $5 \mathrm{~Hz}$ and a temperature of $20^{\circ} \mathrm{C}$. In this case, $20^{\circ} \mathrm{C}$ corresponds to the equivalent design temperature, as defined in the previous section, and the loading frequency corresponds to vehicle speed, with both being standard (and therefore unchangeable) testing criteria.

The project of concern in this paper adopted the Austroads (2012) approach. In this method, the design stiffness is a flexural modulus at the WMAPT (i.e. $42^{\circ} \mathrm{C}$ ) and the loading frequency corresponding to the expected vehicle speed. For a viscoelastic material like asphalt, the correlation between vehicle loading time $(t)$ and loading frequency $(f)$ can be obtained by Equation 4 (BSI, 2012; Nunn, 2004) and the vehicle speed $(V)$ can be approximated by Equation 5 .

4. $f_{\mathrm{PR}}=\frac{1}{2 \pi t}$

5. $V=2 \pi f_{\mathrm{PR}}$ 
Here, $f_{\mathrm{PR}}$ is the frequency of the flexural modulus master curve (in $\mathrm{Hz}$ ) and $t$ is the vehicle loading time (in s).

For the present project, while the flexural modulus was required for the design, only dynamic modulus results were available. As a result, it was necessary to convert these into an equivalent flexural modulus. The frequencies corresponding to vehicle speeds of $100 \mathrm{~km} / \mathrm{h}, 80 \mathrm{~km} / \mathrm{h}$ and $50 \mathrm{~km} / \mathrm{h}$ derived from Equation 5 are approximately $16 \mathrm{~Hz}, 13 \mathrm{~Hz}$ and $8 \mathrm{~Hz}$, respectively. The flexural modulus values at these frequencies can be obtained by developing flexural modulus master curves from laboratory beam fatigue tests in accordance with BS EN 12697-26:2004 (BSI, 2012). However, beam testing was not possible on this project, so further investigation was necessary to convert the design values from dynamic modulus to flexural modulus.

Previous research has shown that, for a given frequency and temperature, the flexural modulus is always less than the dynamic modulus and there is a strong correlation between them (Adhikari et al., 2009; Romanoschi et al., 2006). Kim and Lee (1995) concluded that stiffness is directional in anisotropic mixtures, as is the case for asphalt. Therefore, the differences in stiffness under bending and compression tests are the result of different modes of loading (i.e. flexure and compression, respectively).

As part of the 'asphalt pavement solutions for life' project (Sullivan et al., 2013), the Australian Asphalt Pavement Association investigated the relationship between dynamic modulus and flexural modulus by analysing dynamic modulus values for a large set of asphalt mixes and comparing them with flexural modulus data. It was found that flexural modulus master curves could be derived from dynamic modulus master curves by shifting reduced frequency values by a factor of $\pi$. The relationship between the frequencies from the two tests is

\section{6. $f_{\mathrm{PR}}=\pi f_{\mathrm{CY}}$}

where $f_{\mathrm{PR}}$ is the frequency in a flexural modulus test on a prismatic or trapezoidal beam specimen and $f_{\mathrm{CY}}$ is the frequency in a dynamic modulus test on cylindrical specimens. This relationship was also validated in later studies (Sullivan and Denneman, 2015).

Therefore, the corresponding frequencies for dynamic modulus tests to $100 \mathrm{~km} / \mathrm{h}, 80 \mathrm{~km} / \mathrm{h}$ and $50 \mathrm{~km} / \mathrm{h}$ were calculated to be $5 \mathrm{~Hz}, 4 \cdot 1 \mathrm{~Hz}$ and $2 \cdot 5 \mathrm{~Hz}$, respectively.

\subsubsection{Master curves}

A full characterisation of an asphalt mixture requires a master curve, which defines the viscoelastic material behaviour as a function of both temperature and loading time. Some pavement design methodologies such as the MEPDG require the master curve as a level 1 material input to characterise asphalt over a spectrum of temperatures and traffic classes. However, for the pavement design approach adopted in this project, only one value was required at the design temperature and design vehicle speed. These design inputs at the required frequencies were obtained from master curves.

To derive the dynamic modulus master curves, dynamic modulus tests (frequency sweep) were carried out at $4^{\circ} \mathrm{C}, 20^{\circ} \mathrm{C}$ and $45^{\circ} \mathrm{C}$ on wearing course and base course mixtures. Master curves were developed by shifting the frequency sweep data collected at different test temperatures relative to frequency. The degree of shift is a function of the test temperature $(T)$ and the reference temperature $\left(T_{\mathrm{r}}\right)$ at which the master curve was derived. A shift factor $(a(T))$ defines the required shift to test at a given temperature. This is a constant by which the test frequency must be multiplied to obtain a reduced time to obtain a reduced frequency $\left(f_{\mathrm{r}}\right)$ (Equation 7).

The Williams-Landel-Ferry equation (Equation 8), as defined by Ferry (1980), to model this time (frequency)-temperature principle of viscoelastic materials was used. The sigmoidal function developed by Pellinen et al. (2003) was selected to fit the master curve. The master curves were generated by fitting dynamic modulus values at different frequencies and temperatures to sigmoidal functions and the function parameters were obtained by least-squares optimisation. The solver function in Excel was used for the optimisation, with the parameters summarised in Table 1. The master curves developed for the surface course and base course are presented in Figure 3.

Table 1. Master curve parameters

\begin{tabular}{lcccccc|} 
& $\boldsymbol{\alpha}$ & $\boldsymbol{\beta}$ & $\boldsymbol{\gamma}$ & $\boldsymbol{\delta}$ & $\boldsymbol{C}_{\mathbf{1}}$ & $\boldsymbol{C}_{\mathbf{2}}$ \\
Surface course & 2.21 & -2.36 & 0.48 & 2.22 & 15 & 71 \\
Base & 2.29 & -2.44 & 0.53 & 2.16 & 18 & 96
\end{tabular}

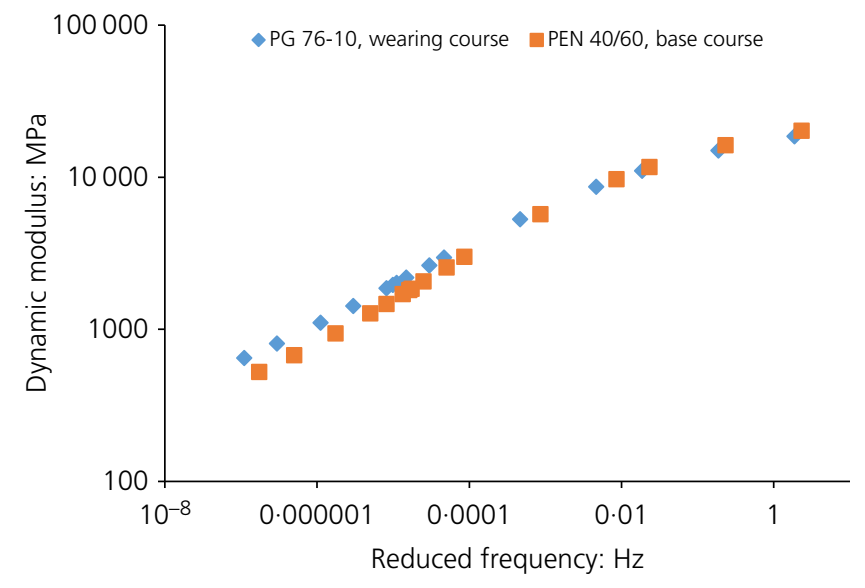

Figure 3. Dynamic modulus master curves 
Using the master curve parameters, dynamic modulus values at the design temperature $\left(42^{\circ} \mathrm{C}\right)$ and frequencies corresponding to $100 \mathrm{~km} / \mathrm{h}, 80 \mathrm{~km} / \mathrm{h}$ and $50 \mathrm{~km} / \mathrm{h}(5 \mathrm{~Hz}, 4 \cdot 1 \mathrm{~Hz}$ and $2 \cdot 5 \mathrm{~Hz}$ ) were calculated. The results are shown in Tables 2 and 3.

The reduced frequency is given by

7. $f_{\mathrm{r}}=f_{\mathrm{CY}} \times a(T)$

8. $\quad \log a(T)=\frac{-C_{1}\left(T-T_{\mathrm{r}}\right)}{C_{2}+T-T_{\mathrm{r}}}$

where $C_{1}$ and $C_{2}$ are regression constants. The dynamic modulus is

9. $\log \left|E^{*}\right|=\delta+\frac{\alpha}{1+\mathrm{e}^{\beta-\gamma \log f_{r}}}$

where $\alpha, \beta, \gamma$ and $\delta$ are sigmoidal model parameters.

Given that the dynamic modulus is the most important material input in the MEPDG, several alternative predictive relationships have been developed to estimate this modulus from simpler material properties and mix volumetrics. The most popular models are the Hirch model (Christensen et al., 2003), the Witczak model (Andrei et al., 1999) and the modified Witczak model (Bari and Witczak, 2006).

Based on these various studies, it was found that the predictive equations serve the purpose of estimating the moduli of different asphalt mixes using known material properties when

Table 2. Design stiffness (flexural modulus) values derived from dynamic modulus and resilient modulus data for wearing course

\begin{tabular}{|c|c|c|c|}
\hline $\begin{array}{l}\text { Equivalent } \\
\text { speed: } \mathrm{km} / \mathrm{h}\end{array}$ & $\begin{array}{l}\text { Design stiffness } \\
\text { from dynamic } \\
\text { modulus master } \\
\text { curve: } \mathrm{MPa}\end{array}$ & $\begin{array}{l}\text { Design } \\
\text { stiffness from } \\
\text { resilient } \\
\text { modulus: } \mathrm{MPa}\end{array}$ & $\begin{array}{c}\text { Rounded } \\
\text { design } \\
\text { value: MPa }\end{array}$ \\
\hline 100 & 1963 & 1925 & 2000 \\
\hline 80 & 1861 & 1828 & 1900 \\
\hline 50 & 1631 & 1597 & 1600 \\
\hline
\end{tabular}

Table 3. Design stiffness (flexural modulus) values derived from dynamic modulus and resilient modulus data for base course

\begin{tabular}{lccc} 
Equivalent & $\begin{array}{c}\text { Design stiffness } \\
\text { from dynamic } \\
\text { modulus master } \\
\text { speed: } \mathbf{k m} / \mathbf{h}\end{array}$ & $\begin{array}{c}\text { Design } \\
\text { stiffness from } \\
\text { resilient } \\
\text { modulus: } \mathbf{M P a}\end{array}$ & $\begin{array}{c}\text { Rounded } \\
\text { design } \\
\text { value: MPa }\end{array}$ \\
\hline 100 & 1813 & 1680 & 1800 \\
80 & 1707 & 1596 & 1700 \\
50 & 1470 & 1420 & 1500 \\
\hline
\end{tabular}

dynamic modulus testing is not practicable. Nonetheless, it is important to note that the accuracy of dynamic modulus predictions needs careful evaluation for different asphalt mix designs in order to predict pavement performance in the field precisely.

\subsubsection{Indirect tensile tests}

In complex modulus (dynamic and flexural modulus) tests, a sinusoidal load, which is characterised by the magnitude of the load (or target deformation) and loading frequency, is applied to the test specimen. In the indirect tensile test, a pulse load is applied, which is characterised by the rise time (or loading time in ASTM D 7369 (ASTM, 2011)) and the rest period along with the target load (or deformation). These pulse load parameters change based on the selected test method. For example, the target rise time for a pulse load in accordance with AS 2891 (SA, 1995) is $0.04 \mathrm{~s}$ while the target rise time in BS DD-213 (BSI, 1993) and BS EN: 2697-26 (BSI, 2012) is $0.124 \mathrm{~s}$. Furthermore, the definition of rise time in these standards is different.

In addition to the pulse load parameters, the method of stiffness calculation changes from standard to standard. For example, the resilient modulus as defined by ASTM D 7369 (ASTM, 2011) and AS 2891 (SA, 1995) is the ratio of applied stress to recoverable strain, whereas in BS DD-213 (BSI, 1993) and BS EN 2697-26 (BSI, 2012), which define ITSM and indirection tension tests on cylindrical specimen tests, strain is derived from the maximum deformation component (Figure 4). Therefore, even if the same pulse load is applied, the resilient modulus is always higher than the ITSM.

Due to the different definitions for indirect tensile tests and differences in pulse load characteristics, it is not possible to derive a relationship between the indirect tensile test and other tests. It is only possible to obtain the equivalent frequency, which can be defined as the frequency under sinusoidal loading that gives the same value of stiffness modulus as that under the pulse load of the indirect tensile test.

Numerous studies have been carried out to determine this equivalent dynamic or flexural modulus frequency (Jameson, 2008; Kumlai et al., 2014; Nunn, 1992; Stempihar, 2015; Xiao, 2009). From these studies, it was found that, for the AS 2891 (SA, 1995) resilient modulus test, the equivalent frequencies for flexural and dynamic modulus are approximately $15 \mathrm{~Hz}$ and $5 \mathrm{~Hz}$, respectively. Using these equivalent frequency values, designers will be able to predict approximate design stiffness values with the help of experience gained on similar materials or by carrying out analysis on available data pertaining to similar materials. For example, the ratio between the dynamic modulus at $42^{\circ} \mathrm{C}$ (design temperature) and that at $25^{\circ} \mathrm{C}$ (test temperature) from the master curve for the wearing course was found to be $0 \cdot 35$. Similarly, the ratio between dynamic moduli at $2 \cdot 5 \mathrm{~Hz}$ and $5 \mathrm{~Hz}$ was found to be 0.83 . 

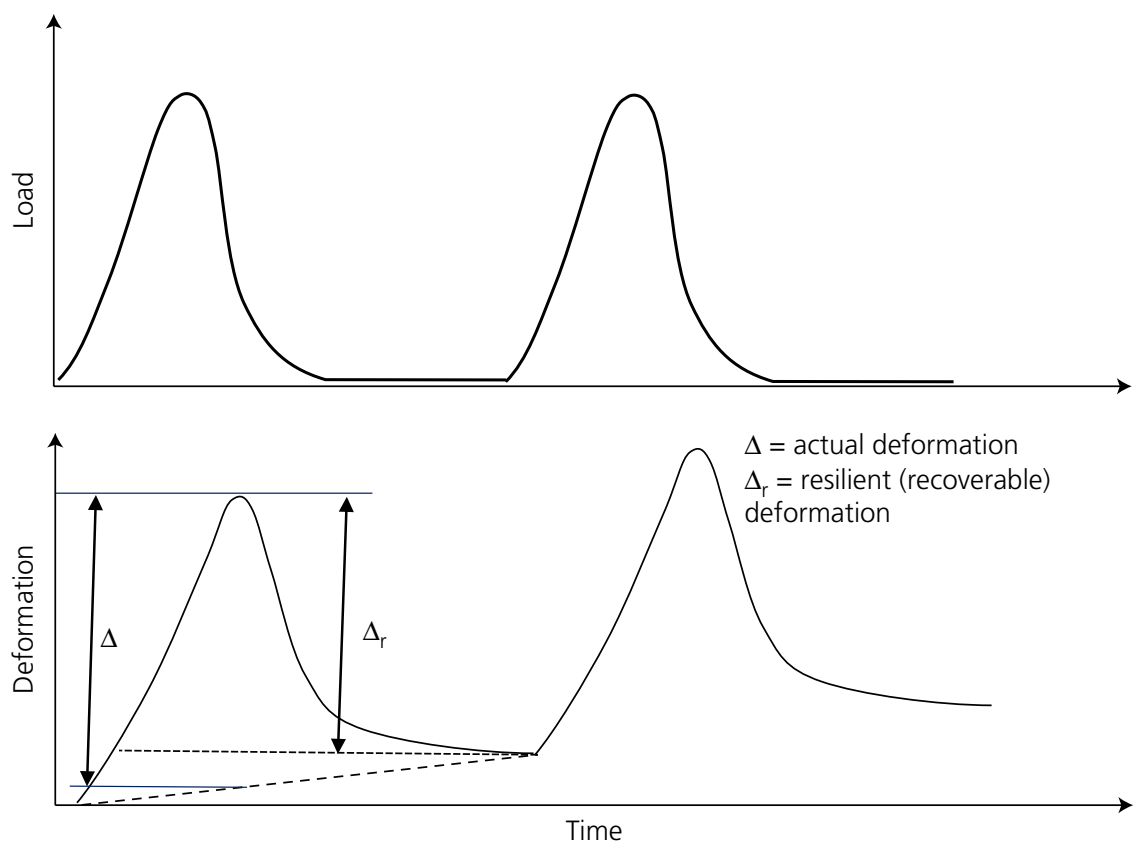

Figure 4. Stress pulse and resulting strain in indirect tensile test

Thus, the resilient modulus obtained from the AS 2891 (SA, 1995) test, which was found to be $5500 \mathrm{MPa}$ for the surface course, can be factored to obtain the design stiffness. In this instance, the design modulus at $100 \mathrm{~km} / \mathrm{h}(5 \mathrm{~Hz})$ was found to be $1925 \mathrm{MPa}(=5500 \times 0.35)$ and $1597 \mathrm{MPa}$ $(=5500 \times 0.35 \times 0.83)$ at $50 \mathrm{~km} / \mathrm{h}$. The same process was applied to base course samples, for which the resilient modulus was found to be $4800 \mathrm{MPa}$. The calculated design stiffness values following this approach are listed in Tables 2 and 3.

\subsubsection{AASHTO coefficients}

The viscoelasticity and temperature dependency of asphalt mixtures must be considered when calculating layer coefficients for an AASHTO empirical pavement design (AASHTO, 1993). However, traditional practice does not usually account for this dependency of behaviour on frequency or vehicle speed.

On this project, this was accomplished by calculating the resilient modulus of the asphalt layers from the dynamic modulus master curve, as discussed in the previous section. As a first step, the pavement temperature was calculated using one of the methods discussed previously. From the dynamic modulus master curve, individual dynamic modulus values were obtained corresponding to the temperatures and the loading frequency. Finally, these values were converted into the AASHTO layer material coefficients using figure 2.1 of AASHTO (1993).

\section{Cement-bound bases}

In a conventional, fully flexible pavement, the asphalt base is the layer that provides the majority of the structural capacity. This type of pavement is designed such that adequate thickness is provided to protect the subgrade from excessive rutting and avoid fatigue cracking by limiting the tensile strain at the bottom of the asphalt.

In composite pavements, the design should also consider reflective cracks that may propagate through the asphalt layer as a result of shrinkage cracking in the cement-bound layer. These are not cracks that may develop as a result of a structural deficiency, but rather a natural characteristic of CBMs. These reflective cracks are a result of both environmentally induced stresses (thermal expansion, contraction and wrapping) and traffic-induced stresses (bending and shear) (Lytton, 1989; Nunn, 1989). The maximum stresses in the asphalt overlay of a composite pavement will likely occur at these shrinkage points, making it the most likely location for crack growth to initiate and propagate into the asphalt layer and reflect at the surface.

Many studies have been carried out to develop models to predict this reflective crack propagation mechanism (Lytton et al., 2010). These prediction models range from pure empirical models to more advanced FEMs embedded with fracture mechanics theories such as the Paris law. For example, Capa-3D is a three-dimensional FEM-based pavement analysis tool developed at Delft University of Technology (Scarpas, 2004). The tool is capable of simulating pavement interlayers and interfaces and is embedded with a finite-element remeshing technique to simulate crack propagation ( $\mathrm{Hu}$ et al., 2008). These features make Capa-3D an effective tool to analyse reflective cracks and crack propagation in asphalt. However, the implementation of such tools in engineering 
designs requires more material inputs and time than is practicable and the application of such tools has therefore been limited to research and some specialist engineering problems. As a result, this paper is limited to discussion of a rational approach based on multi-layer elastic models without loss of too much accuracy.

In the current design, a sufficiently thick asphalt layer was provided based on analytical design with the assumption that the CBM layer will crack during curing. Adopting such an approach does not structurally compromise the asphalt during the design life of the pavement. In these pavements, the critical tensile stress (or strain) location for flexural fatigue is a location on the bottom of the cement-bound base, in addition to tensile strain in the bottom of the asphalt surface and compressive strain in the top of the subgrade. Therefore, composite pavements should be designed for the following design criteria.

(a) Tensile stress at the bottom of the cement-bound base (fatigue in cement-bound base) is limited.

(b) Tensile strain at the bottom of the asphalt surface at the cracked location (reflective crack in asphalt surface) is limited.

(c) Compressive strain at the top of the subgrade (rutting in the subgrade) is limited.

However, the rationale for the above criteria is that the CBM base layer modulus needs careful consideration when used as input in pavement analysis.

The present discussion is applicable to pavements with weak CBM bases that are designed to crack. Pavements with strong CBM bases and thick asphalt overlays are usually designed not to crack, except for induced cracking or pre-cracking. In such cases, a post-crack phase of the pavement is also included in the calculations. This two-phase calculation methodology is embedded in the Australian and French design methodologies (Austroads, 2012; LCPC and Setra, 1997).

In this case, the pavements are designed using a weak CBM base with a compressive strength of $4.5 \mathrm{MPa}$ (typically tensile strength is less than $0.5 \mathrm{MPa}$ ). This creates a CBM that is weak enough to crack even for a temperature drop of $5^{\circ} \mathrm{C}$. Thus, maximum deflection of the asphalt layer under a wheel load will occur at these cracks, making them the most likely location for in initiation of crack growth. Such cracks also mean that the in situ layer stiffness is less than that of the precracked stiffness measured in the laboratory and it is this in situ stiffness that governs the load spread to the underlying layers and the subgrade. Therefore, the methodology adopted the following interpretations within the design to develop each performance criteria.

(a) The fatigue criteria for CBM bases are usually governed by the tensile stress (stress ratio) at the bottom of the base. The tensile stress increases with increases in modulus, which means that the criteria to limit tensile stress at the bottom of the CBM should be based on structural analysis using the pre-cracked modulus.

(b) Higher tensile strains at the bottom of asphalt layers tend to develop at the locations where the CBM base cracks. Therefore, the recommended input for the CBM structural analysis is the 'equivalent post-crack modulus' (which is the artificially 'downgraded pre-crack modulus').

(c) Compressive strain at the top of the subgrade is a function of the modulus of the layers above it. For the same thickness, the higher the modulus of the layers, the lower the compressive strain at the top of the subgrade. Therefore, the recommended input for the CBM modulus is the artificially downgraded modulus.

The pre-cracked stiffness modulus used in the analysis to determine the fatigue criteria in the CBM was $10000 \mathrm{MPa}$. This is typical of a laboratory stiffness modulus for a compressive strength of $4.5 \mathrm{MPa}$ for a CBM made of crushed limestone. As a general rule, a load-induced stress ratio of 0.5 is recommended based on laboratory fatigue tests for a long pavement life (Thom, 2010). To account for thermally induced stresses, a factor of $1 \cdot 2$ to $2 \cdot 0$ is applied depending on the crack spacing. This results in a combined stress ratio of $0 \cdot 25$ to 0.40. Along similar lines, Highways England (2006) recommends a combined stress ratio of $0 \cdot 23-0 \cdot 33$ for indeterminate life pavements depending on the strength of the CBM.

The downgraded stiffness modulus to be used in response analysis for the asphalt layer and subgrade strain values is the effective stiffness of the cracked CBM layer. This effective stiffness is a function of the crack spacing, the amount of slip at the crack (i.e. interlock) and the materials' intrinsic properties. Thom and Cheung (1999) presented a theoretical method for estimating the effective stiffness based on the hinge effect (angular rotation) and slip effect (relative vertical movement) at the crack. The calculations require the slip modulus of the crack, measured in situ. The measurement of such values using a falling weight deflectometer prior to the design process was impractical. Therefore, the guidance recommended by LCPC and Setra (1997) to establish an effective stiffness for the postfatigue phase was adopted in this study. The recommended effective stiffness value is one-fifth of the pre-cracked material modulus. Thus, an effective stiffness value of $2000 \mathrm{MPa}$ was adopted for pavement response analysis of the critical strain in the asphalt overlay and subgrade. This is believed to be a valid assumption for a weak CBM that tends to develop closely spaced cracks, typically at about $1 \mathrm{~m}$ spacing and with good interlock. The critical strain values at the bottom of the asphalt overlay and the top of the subgrade were determined with effective stiffness inputs and compared with allowable values. 


\section{Granular materials}

For empirical flexible pavement design methods such as AASHTO (1993), granular materials are usually characterised by a shear strength parameter such as the California bearing ratio (CBR). The in situ CBRs of these materials depend on factors such as moisture content, density, Atterberg limits and so on. The required thickness of asphalt above the granular layer(s), which is derived using design charts or equations, is governed by its CBR value. Where analytical methods are adopted for pavement design, granular materials are instead characterised by their elastic parameters such as elastic modulus and Poisson's ratio.

In addition to the parameters that influence the CBR, the modulus of granular material is dependent on the stress applied. Unlike asphalt, the behaviour of granular material is independent of vehicular loading. Therefore, for pavement design purposes, the modulus value is primarily dependent on in situ characteristics and stress levels generated in these layers by vehicular (axle) loads. The stress dependency of granular materials can be approximately modelled in layered linear elastic models by sub-dividing the layer into multiple sublayers. Each sub-layer is then assigned a modulus value that corresponds to the stress level the sub-layer is experiencing. This stress-dependent modulus can be obtained by carrying out repeated-load triaxial tests under in situ conditions and stress levels that can be determined preliminarily using linear elastic models.

Under thick asphalt layers, most of the stresses are absorbed by the surfacing and the stress applied to the granular layers is reduced. Consequently, the modulus of the granular layer is reduced. Typically, specified values for granular materials are in the region of $150-210 \mathrm{MPa}$, which also corresponds to the standard AASHTO coefficients for these materials of 0.13 (subbase) and 0.14 (base).

However, in Qatar, the design temperature is high and, although the asphalt was relatively thick, the low stiffness modulus of the asphalt means that higher stresses would be transferred to the granular layers. As a result, it was possible to use a higher stiffness modulus (up to $300 \mathrm{MPa}$ ) than, for example, that used in temperate climates such as in the UK.

The Poisson's ratio of granular material is typically in the range $0 \cdot 15-0 \cdot 45$. However, when used for analytical design, the value chosen was found to have little impact on the pavement thickness. In developing the design for this project, a Poisson's ratio of 0.35 was adopted.

\section{Summary}

The content of this paper is based on a project undertaken by Mott MacDonald in the State of Qatar. International design practice, knowledge and research into pavement materials was applied to engineering practice and subsequently into the construction of a highway pavement in a hot climate, where pavement surface temperatures can be as high as $70^{\circ} \mathrm{C}$. The best practices in the selection of pavement design parameters such as pavement temperature, asphalt design stiffness for analytical design and asphalt layer coefficients for AASHTO empirical pavement design (AASHTO, 1993) were discussed. The equivalent design temperature, which is dependent on the method of calculation, was identified as the most important parameter in the pavement design process. It was also found that, to calculate the design temperature accurately, the pavement temperature distribution throughout the year is required. The most accurate way to obtain such data is to measure it directly from the pavement. In the absence of such measurements, metrological data collected near the project location can be used to derive design temperatures from empirical models.

A conversion procedure to approximate the asphalt stiffness modulus at the design temperature and vehicle speed from stiffness values derived from different test methods was proposed. A rational approach to addressing the challenges encountered in the design of weak cement-stabilised bases was also discussed.

\section{Acknowledgements}

The authors would like to acknowledge colleagues within the Pavement Team at Mott MacDonald, in particular Iain MacGregor, for their assistance during this project.

\section{REFERENCES}

AASHTO (American Association of State Highway and Transportation Officials) (1993) Guide for Design of Pavement Structures. AASHTO, Washington, DC, USA.

Adhikari S, Shen S and You Z (2009) Evaluation of fatigue models of hot-mix asphalt through laboratory testing. Transportation Research Record 2127: 36-42.

Asphalt Institute (1981) Manual Series No. 1: Thickness DesignAsphalt Pavements for Highways and Streets. Asphalt Institute, College Park, MD, USA.

Andrei D, Witczak MW and Mirza MW (1999) Development of a Revised Predictive Model for the Dynamic (Complex) Modulus of Asphalt Mixtures. University of Maryland, College Park, MD, USA, Inter Team Technical Report prepared for the NCHRP 1-37A Project.

ARA (Applied Research Associates) (2001) Guide for Mechanistic-Empirical Design of New and Rehabilitated Pavement Structures. ARA, Champaign, IL, USA.

ASTM (2011) D 7369: Standard test method for determining the resilient modulus of bituminous mixtures by indirect tension test. ASTM International, West Conshohocken, PA, USA.

Austroads (2012) Guide to Pavement Technology Part 2: Pavement Structural Design. Austroads Ltd, Sydney, Australia.

Bari J and Witczak WM (2006) Development of a new revised version of the Witczak predictive model for hot mix asphalt mixtures. Journal of the Association of Asphalt Paving Technologists 75: $381-423$.

BSI (1993) BS DD-213:1993: Method for determination of the indirect tensile stiffness modulus of bituminous mixtures. BSI, London, UK.

BSI (2010) BS 594987:2010: Asphalt for roads and other paved areas. Specification for transport, laying, compaction and type testing protocols. BSI, London, UK.

BSI (2012) BS EN 2697-26:2012: Bituminous mixtures - test methods for hot mix asphalt - Part 26: stiffness. BSI, London, UK. 
Christensen JDW, Pellinen K and Bonaquist RF (2003) Hirsch model for estimating the modulus of asphalt concrete. Journal of the Association of Asphalt Paving Technologists 72: 97-121.

Claessen AIM, Edwards J, Sommer P and Uge P (1977) Asphalt pavement design: the shell method. Proceedings of the 4th International Conference on Structural Design of Asphalt Pavements, Ann Arbor, MI, USA, vol. 1, pp. 39-74.

EC (European Commission) (1999) COST 333: Development of New Bituminous Pavement Design Method. EC, Brussels, Belgium.

Ferry JD (1980) Viscoelastic Properties of Polymers, 3rd edn. Wiley, New York, NY, USA.

Highways England (2006) Pavement Design. Design Manual for Roads and Bridges, Volume 7, Section 2 (HD 26/06). Highways England, Birmingham, UK.

Hu S, Hu X and Zhou F (2008) Using semi-analytical finite element method to evaluate stress intensity factors in pavement structure. In Pavement Cracking: Mechanisms, Modeling, Detection, Testing and Case Histories (Al-Qadi IL, Scarpas T and Loizos A (eds)). CRC Press, Leiden, the Netherlands, pp. 637-646.

Jameson G (2008) Technical Basis of Austroads Guide to Pavement Technology: Part 2: Pavement Structural Design. Austroads Ltd, Sydney, Australia.

Kim YR and Lee YC (1995) Interrelationships among stiffness of asphaltaggregate mixtures. Journal of the Association of Asphalt Paving Technologists 64: 575-609.

Kumlai S, Jitsangiam P and Nikraz H (2014) Comparison between resilient modulus and dynamic modulus of Western Australia hot mix asphalt based on pavement design perspective. Proceedings of the 26th ARRB Conference, Sydney, NSW, Australia.

LCPC and Setra (Laboratoire Central des Ponts et Chausees and Service d'Etudes Techniques des Routes et Autoroutes) (1997) Design Manual for Pavement Structures. LCPC, Paris, France.

Lytton R (1989) Use of geotextiles for reinforcement and strain relief in asphalt concrete. Geotextiles and Geomembranes $\mathbf{8 ( 3 )}$ : 217-237.

Lytton RL, Tsai FL, Lee S et al. (2010) Models for Predicting Reflection Cracking of Hot-Mix Asphalt Overlays. Texas A\&M University, College Station, TX, USA, NCHRP Report 669.

Nunn ME (1989) An investigation of reflection cracking in composite pavement in the United Kingdom. Proceedings of the 1st International RILEM Conference on Reflective Cracking in Pavements, Brussels, Belgium.

Nunn ME (1992) Towards a performance specification for bituminous roadbase. Proceedings of the 7th International Conference on Asphalt Pavements, Nottingham, UK, pp. 266-279.
Nunn ME (2004) Development of a More Versatile Approach to Flexible and Flexible-Composite Pavement Design. TRL Limited, Crowthorne, UK, Report 615

Pellinen TK, Witczak MW and Bonaquist RF (2003) Asphalt mix master curve construction using sigmoidal fitting function with non-linear least squares optimization. Proceedings of 15th Engineering Mechanics Division Conference, New York, NY, USA.

Romanoschi S, Dumitru N and Dumitru O (2006) Resilient Modulus and the Fatigue Properties of Kansas Hot Mix Asphalt Mixes. Kansas State University, Manhattan, KS, USA, Report K-TRAN: KSU-02-6.

SA (Standards Australia) (1995) AS 2891.13.1-1995: Methods of sampling and testing asphalt, method 12.1: determination of the resilient modulus of asphalt - indirect tensile method. SA, Sydney, Australia.

Scarpas A (2004) A Mechanics Based Computational Platform for Pavement Engineering. PhD thesis, Delft University of Technology, Delft, the Netherlands.

Shell (1978) Pavement Design Manual: Asphalt Pavement and Overlays for Road Traffic. Shell International Ltd, London, UK.

Stempihar J (2015) Resilient Modulus to Dynamic Modulus Relationship and Pavement Analysis with the Mechanistic-Empirical Pavement Design Guide. Arizona State University, Grove City, PA, USA.

Sullivan B and Denneman E (2015) Inter-conversion of Australian modulus test methods. Proceedings of the 16th AAPA International Flexible Pavements Conference, Gold Coast, QLD, Australia.

Sullivan B, Rickards I and Yousefdoost S (2013) Interconversion of laboratory measured modulus results to field modulus and strain. Proceedings of the 15th AAPA International Flexible Pavements Conference, Brisbane, QLD, Australia.

Thom NH (2010) Principle of Pavement Engineering. Thomas Telford, London, UK.

Thom NH and Cheung LW (1999) Relating in situ properties of cementbound bases to their performance. Transportation Research Record 1673: 3-8.

Witczak MW (1972) Design of full depth asphalt airfield pavement. Proceedings of 3rd International Conference on the Structural Design of Asphalt Pavements, London, UK.

Witczak MW, Bonaquist R, Von Quintus H et al. (2000) Specimen geometry and aggregate size effects in uniaxial compression and constant height shear tests. Journal of the Association of Asphalt Technologists 69: 733-793

Xiao Y (2009) Evaluation of Engineering Properties of Hot Mix Asphalt Concrete for the Mechanistic Empirical Pavement Design. PhD thesis, Florida State University, Tallahassee, FL, USA.

\section{How can you contribute?}

To discuss this paper, please email up to 500 words to the editor at journals@ice.org.uk. Your contribution will be forwarded to the author(s) for a reply and, if considered appropriate by the editorial board, it will be published as discussion in a future issue of the journal.

Proceedings journals rely entirely on contributions from the civil engineering profession (and allied disciplines). Information about how to submit your paper online is available at www.icevirtuallibrary.com/page/authors, where you will also find detailed author guidelines. 